\title{
Modelling the butterfat crystallisation process
}

\author{
G. Heyen 1, X. Alleman 1, B. Kalitventzeff 1, D. Dalemans 2 \\ 1 : Laboratoire d'Analyse et Synthèse des Systèmes Chimiques, Université de Liège, \\ Sart Tilman B6A, B-4000 Liège (Belgium), tel +32 4 3663521, FAX +32 4 3663525, \\ email G.Heyen@ulg.ac.be \\ 2 : Corman s.a., B4834 Goé (Belgium)
}

\begin{abstract}
Milk fat exhibits seasonal variations in composition and properties which are undesirable for many subsequent applications. Thus techniques are sought to process dairy products in order to achieve a consistent quality. A brief introduction to milk fat presents its most important particularities, especially composition, seasonal variations, solid fat content, crystallisation and polymorphism.

The differential scanning calorimetry (DSC) analysis allows to estimate the solid fat content. Different methods have been developed to estimate more and more precisely the solid fat content which is certainly an important parameter in the description of the textural properties of butterfat.

The industrial crystallisation process is modelled on the basis of pilot plant data. That model allows to approach the particular temperature profile in the scraped surface heat exchangers and to give a first explanation of the involved phenomena.
\end{abstract}

Keywords : Butterfat, Solid fat content, Crystallisation, Dairy process modeling, Texturization, Triglycerides.

\section{INTRODUCTION}

Milk fat is a natural product and is therefore subject to seasonal variations in composition. Those lead to properties variations, specially in texture, undesirable for many subsequent applications.

Thus milk fat is separated into several fractions, obtained by temperature controlled crystallisation. These fractions are then mixed in such proportions that the resulting product presents the desired texture.

On one hand, the solid fat content (SFC) seems to be a very important parameter to characterise the milk fat texture. Thus we tried to achieve the most precise indication about it. This has been obtained by differential scanning calorimetry analysis (DSC).

On the other hand, the butterfat crystallisation process has been modelled using pilot plant data. The pilot plant is composed of three scraped surface heat exchangers and one resting tube. This model shows mainly the temperature profile in the heat exchangers and allows a first explanation of the involved phenomena.

Finally, a microscopic analysis of milk fat has shown that crystal shape must be taken into account to characterise the textural properties, and depends on the crystallisation conditions.

\section{ABOUT MILK FAT}

Milk fat is a very complex natural product containing over 250 different triglyceride species. No single molecular species is present at greater than about $4 \%$ (on a molar basis) so that its phase behaviour and physical properties are truly mixed properties. However, milk fat can be described as a mixture of three kinds of triglycerides, based on their melting point: the high-melting triglycerides above $40{ }^{\circ} \mathrm{C}$, the middle-melting triglycerides between 15 and $40{ }^{\circ} \mathrm{C}$ and the lower-melting triglycerides below $15{ }^{\circ} \mathrm{C}$. Thus, at room temperature, milk fat is a mixture of liquid and solid, characterised by his solid fat content (SFC). This is about $15 \%$ at room temperature. Plastic fats are formed when the solid fat content is over $12-15 \%$. Below this level the fat is pourable and at SFC over $15 \%$ the fat is brittle and fractures rather than flows. The SFC variation with temperature can be evaluated by differential scanning calorimetry (DSC). This method will be described in details later.

Besides, seasonal and geographic variation in milk fat composition can occur due to its natural origin. Since the textural properties of fat are determined by the fatty acids and triglycerides composition, these variations induce very large changes in textural properties. For example, winter and summer butters have slightly different compositions. These variations are such that a summer butter is less firm than a winter butter at the same temperature.

The crystalline behaviour of milk fat needs some supplementary explanation: it exhibits crystal polymorphism. Each kind of triglyceride can occur with different crystalline forms : the $\alpha, \beta$, and $\beta$ phases, from the less to the more stable phase. These phases are characterised by their melting temperature and enthalpy.

\section{SOLID FAT CONTENT ESTIMATION BY DIFFERENTIAL SCANNING CALORIMETRY}

The differential scanning calorimetry allows to study the variations of the SFC with temperature. But previous to any development, lets us examine the shape of the DSC curve of milk fat (Figure 1).

The curve shown in Figure 1 is not unique for milk fat. In fact, its shape can be modified by the crystallisation conditions (polymorphism). Thus this curve is representative but not unique. The melting interval covers the temperature range from about -100 ${ }^{\circ} \mathrm{C}$ to $40{ }^{\circ} \mathrm{C}$. Two major peaks are visible : the first one between 0 and $20{ }^{\circ} \mathrm{C}$ corresponds to the oleic 
fraction and the second one, between 20 and $40{ }^{\circ} \mathrm{C}$, corresponds to the stearic fraction.

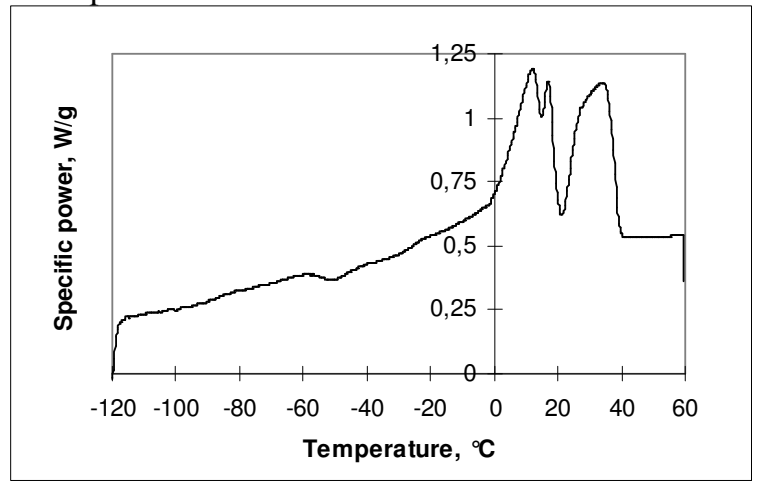

Figure 1 : Milk Fat DSC Curve

By modelling the DSC analysis, a general methid can be developed to estimate the solid fat content.

The DSC curve can be divided in $n$ identical temperature intervals identified by their limiting temperatures $T_{i}$ and $T_{i+1}$, and the corresponding SFC, $\mathrm{x}_{\mathrm{i}}$ and $\mathrm{x}_{\mathrm{i}+1}$ for the $i$ interval (see Figure 2).

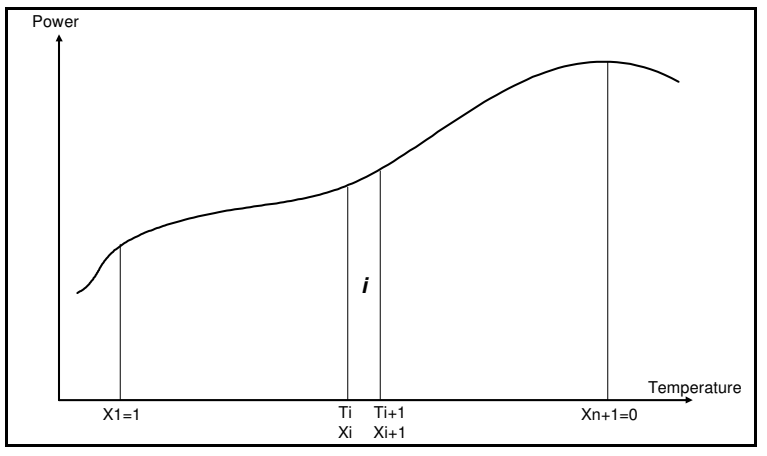

Figure 2 : DSC Curve Discretisation

For each temperature interval, a thermal balance can be written : the heat supplied by the analyser $\left(\mathrm{Q}_{\mathrm{i}}\right)$ to heat up the milk fat by $\Delta \mathrm{T}=\mathrm{T}_{\mathrm{i}+1}-\mathrm{T}_{\mathrm{i}}$ is the sum of two contributions, namely the melting heat and the specific heat in the considered interval. Thus :

$$
Q_{i}=\left(\breve{x}_{i} C_{p}^{S}+\left(1-\breve{x}_{i}\right) C_{p}\right) \cdot\left(T_{i+1}-T_{i}\right)+\Delta H_{i}^{f}\left(x_{i}-x_{i+1}\right)
$$

where $\mathrm{C}_{\mathrm{p}}^{\mathrm{s}}, \mathrm{C}_{\mathrm{p}}{ }^{1}$ and $\Delta \mathrm{H}_{\mathrm{i}}^{\mathrm{f}}$ denote the solid and liquid phase specific heat and the melting enthalpy of the fat fraction melting between $T_{i}$ and $T_{i+1}$.

Besides these $n$ equations, two boundary conditions can be written : they formulate that in the first temperature interval the SFC is equal to 1 (solid state) and in the last one the SFC is equal to 0 (liquid state). The unknowns in each interval are the $\operatorname{SFC}\left(\mathrm{x}_{\mathrm{i}}\right)$ and the melting enthalpy $\left(\Delta \mathrm{H}_{\mathrm{i}}^{\mathrm{f}}\right)$ in the considered interval. To solve for $2 n+1$ unknowns, $n$ - 1 additional constraints must be provided. Three different sets of hytpothesis have been compared to find those $n-1$ missing equations.

The first one is based on the assumption that the SFC variation is linear with temperature. This provides the $n-1$ missing equations. The distribution ofmelting enthalpy with melting temperature can be estimated on this basis, as shown in Figure 3. However this variation of melting enthalpy with temperature is not conformed when DSC measurements are carried out on purified butterfat samples obtained by fractionation.

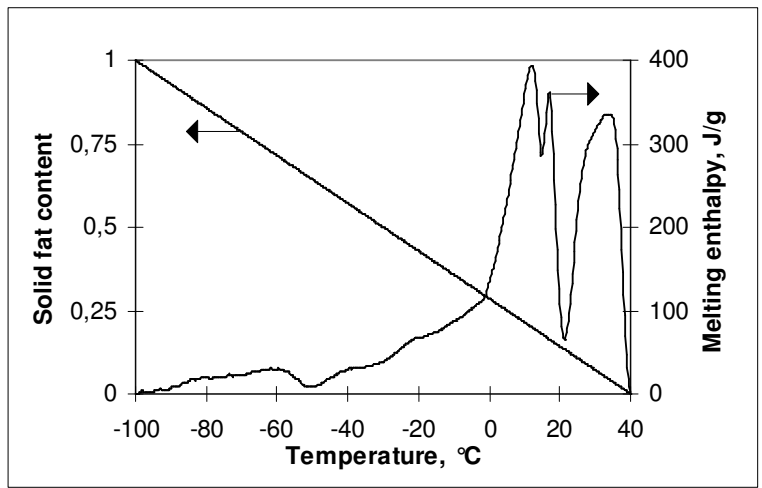

Figure 3 : First Method

As a second hypothesis, we assume that the melting enthalpy has a constant value for all the fractions. This assumption leads to better results, shown in Figure 4. This method can again be improved by using all available information about the variation of melting enthalpy with temperature.

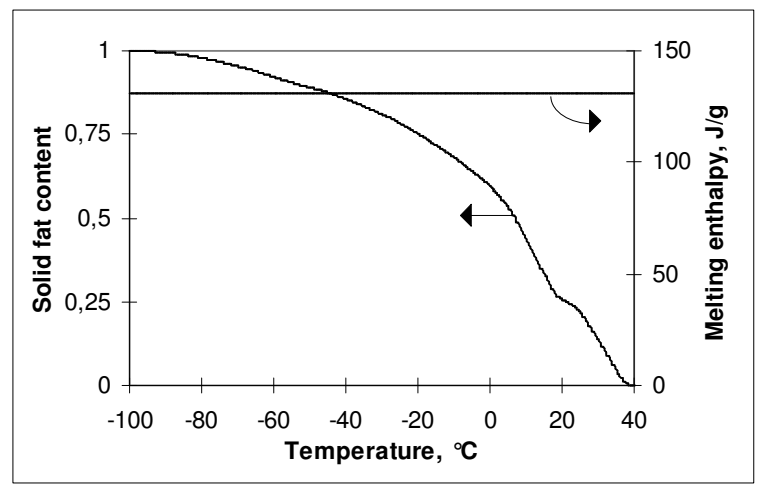

Figure 4: Second Method

The third method is based on the application of the second method to fractions obtained by controlled temperature crystallisation. Indeed, for any fraction, we can assume that the melting enthalpy is constant. So it is possible to determine the melting enthalpy of each fraction and to draw the enthalpy distribution with temperature. We can now determine the SFC distribution without any other assumption. The results obtained by considering two fractions (oleic and stearic fractions) are shown in Figure 5. The calculated SFC variation corresponds well to independent estimations based on spectral measurements (e.g. pulsed NMR).

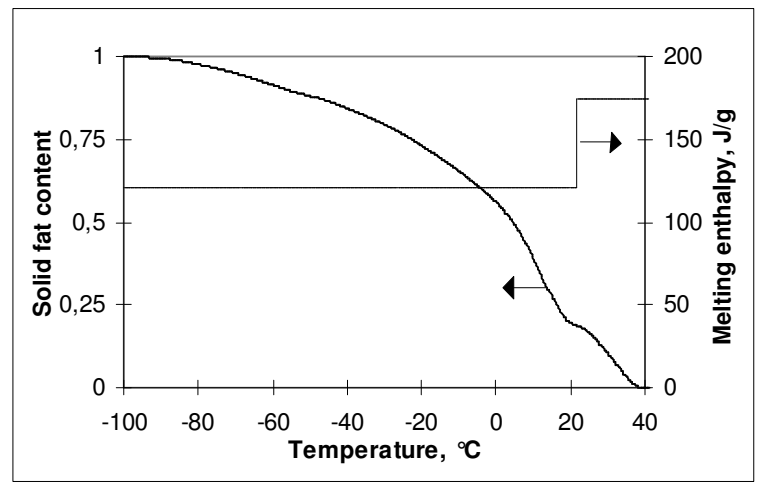

Figure 5: Third Method 
Figure 6 allows to compare the three estimation methods. We know that the third method is the best one because its assumptions are the less restrictive. However since it does not differ a lot from the second one, using a more complex distribution of the melting enthalpy is not espected to modify sharply the results.

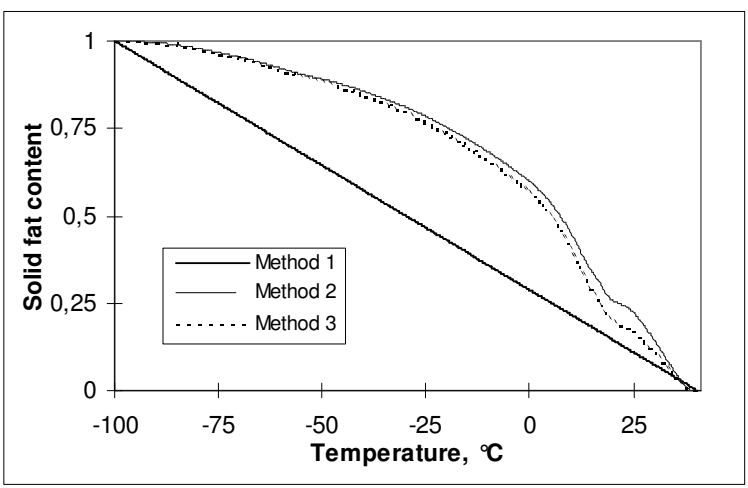

Figure 6 :Three methods comparison

The SFC curve calculated by the third method points out that the SFC at room temperature is lower than $20 \%$ but from a macroscopic point of view, the matter presents nevertheless a solid aspect. This is due to the particular structure of the crystals that can hold much liquid between their dendrites (see below the Butterfat microscopic analysis).

\section{MODELLING THE CRYSTALLISATION PROCESS}

Measurements were obtained from a pilot plant, using a normalised butterfat mixture. The pilot plant is composed of a feed pump supplying melted butterfat to 3 scraped surface heat exchangers and a resting tube connected in series.

A scheme of these scraped surface heat exchangers is given in Figure 7.

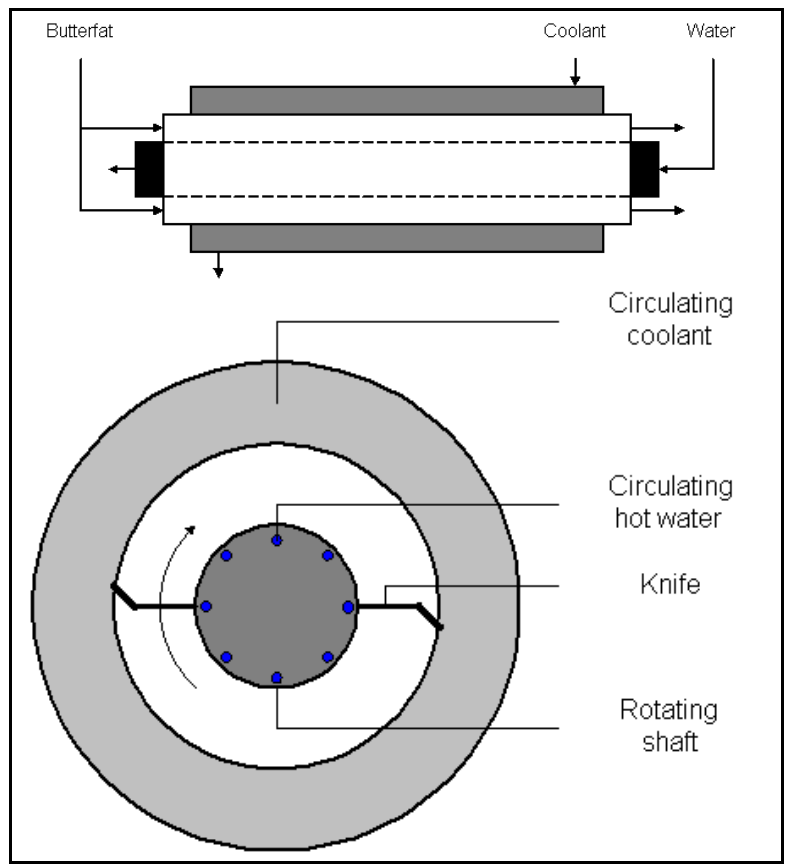

Figure 7 : Section in a scraped surface heat exchanger
The butterfat flows inside a tube whose wall is externally cooled. The inner surface is scraped by rotating knives, whose function is double : they avoid the solid butterfat accumulation on the exchange surface and they mix the solid butterfat to the liquid butterfat. The shaft supporting the knives is warmed up with circulating hot water to avoid the butterfat to stick and turn with the shaft.

Only the heat exchangers have been modelled on the basis of some pilot plant data, namely for each heat exchanger :

- the flowrate, inlet and outlet temperatures of butterfat;

- the flowrate, inlet and outlet temperatures of the water used to keep the axis warm ;

- the power supplied to the rotating shaft ;

- the temperature of the coolant (a boiling refrigerant).

Based on the pilot plant data, the crystallisation process has been modelled. This model is based on the solution of the thermal balance of the heat exchangers. Butterfat and hot water flows are counter current. The thermal balance consider the following components :

- the exchange between the hot shaft and the butterfat;

- the exchange between the butterfat and the coolant ;

- the energy dissipation in the butterfat due to the rotating knives.

Concerning the transfer across the scraped surface (butterfat to refrigerant heat transfer), two published correlations were compared to experimental data. The first correlation, very theoretical, is insufficient ; the second correlation, experimental, seems to be accurate to model the considered scraped surface heat transfer.

No published correlation was found to predict the transfer between the hot rotating shaft and the butterfat, where the transfer surface is not scraped. Thermal convection is influenced by two causes : the first one is the rotation of the shaft in the butterfat and the second one the butterfat longitudinal flow trough the heat exchanger. Besides, the rotating knives induce some mixing of the butterfat. So very complex heat transfer phenomena are in presence : mixed fluid and convective transfer. We tried to represent them by an experimentally adjusted overall heat transfer coefficient.

All the power supplied to the shaft was supposed to be converted to heat and dissipated by the rotating knives. This energy has been supposed to be equally distributed on all the length of the heat exchanger.

Simulation based on this model allows to determine the temperature profiles shown in Figure 8 . 


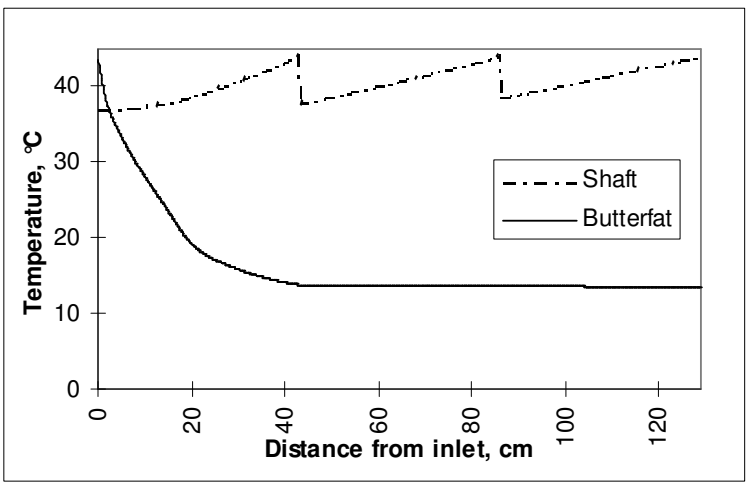

Figure 8 :Temperature profiles

Note first that the shaft temperature profile discontinuities are due to the transition from one to another exchanger in the line : each heat exchanger has its own hot water flow.

The butterfat temperature profile indicates that the main temperature change occurs in the first half of the first heat exchanger. In the rest of the line, the crystallising butterfat remains at approximately constant temperature : the energy exchanged with the heated shaft balances almost exactly the heat transferred to the refrigerant. The very fast cooling down in the first half of the first exchanger induces an important nucleation ; in the rest of the line, the nearly constant temperature allows the butterfat crystallisation and phases changes. However the intensive agitation and shear is likely to have a significant influence on the final product quality.

To determine the butterfat temperature profile, the enthalpy function of butterfat has to be known. But this one depends on the crystallisation conditions. It has been approximated by the experimental enthalpy curve obtained by running a DSC analysis with a very slow temperature change, thus achieving near equilibrium conditions.

To improve the model the enthalpy curve at equilibrium should be replaced by a complete crystallisation model. Such a crystallisation model is very complex because of the important number of parameters to be taken into account : the very large number of components in the mixture and their very particular behaviour. About behaviour we could point out the polymorphism and the solid solutions formation

\section{BUTTERFAT MICROSCOPIC ANALYSIS}

Samples of crystallised butterfat have been examined by microscopic techniques. Observation confirms traditional theories about crystal formation, that envision a three dimensional network held together by Vander Waals forces. Figure 9 shows such a crystalline structure. The butterfat crystals are made of long mixed filaments called dendrites.

We also have explored the opportunities of microscopic techniques to provide important crystallisation parameters. We were able to determine the crystal size distribution and the fractal nature of the crystal network. So those microscopic techniques could be helpful to validate a crystallisation model.

Up to now, we were not able to examine directly samples obtained in the pilot plant because we were obliged to melt the butterfat in order to prepare the sample and by melting we destroyed the initial crystals structure. We have thus to find a way to prepare samples without melting them.

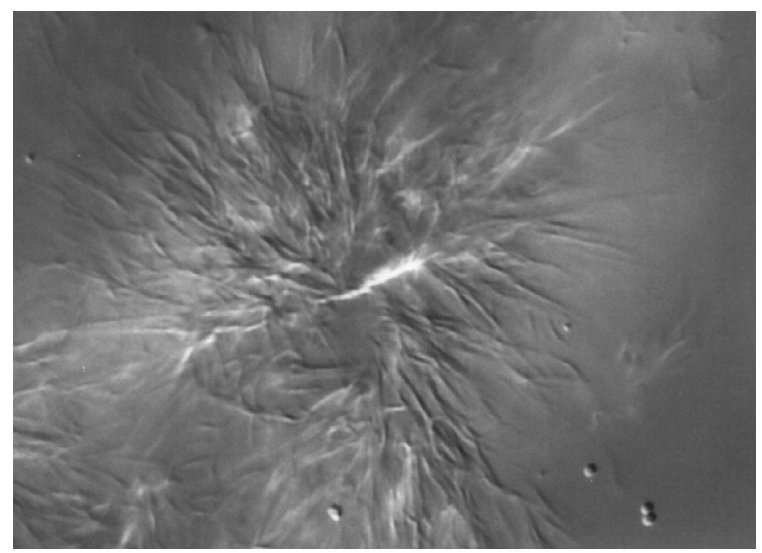

Figure 9 : Butterfat crystals structure

\section{CONCLUSIONS}

The study has not provided a definitive answer to the very complex problem of the butterfat crystallisation process. It has however clarified some important points that are the solid fat content estimation by DSC and the temperature profile in the scraped surface heat exchangers.

Besides, interesting perspectives have been shown that could be very helpful in future works ; they are especially the butterfat microscopic analysis.

\section{REFERENCES}

Elisabettini P. et al., «Polymorphism of Stabilized and Nonstabilized Tristearin, Pure and in Presence of Food Emulsifiers », JAOCS, Vol. 73, n² (1996), pp. 187-192.

Fractal Fats and Polymorphic Fats: Plastic Fat Rheology Is Governed by the Fractal Nature of the Fat Crystal Network and by Crystal polymorphism. Alejandro G. Marangoni, International Conference on the Physical Properties of Fats, Oils, and Emulsifiers with Application to Foods, September 21-25, 1997, Chicago, Illinois

Alleman $X$., «Modélisation de la texturation de matière grasse butyrique », ULg, 1998.

Mc Cabe, Smith \& Harriot, «Unit operations of Chemical Engineering », Fifth edition.

Lavigne $F$., «Polymorphisme et Transitions de Phases des Triglycérides. Application aux propriétés thermiques et structurales de la matière grasse laitière anhydre et de ses fractions. ", Thèse de doctorat, E.N.S.I.A., France, 1995 